\title{
Teaching Circuit Theory using a Desktop VR System
}

\author{
http://dx.doi.org/10.3991/ijep.v3i4.2701 \\ M. Travassos Valdez ${ }^{1}$, C. Machado Ferreira ${ }^{1}$ and F. P. Maciel Barbosa ${ }^{2}$ \\ ${ }^{1}$ Instituto Superior de Engenharia de Coimbra, Coimbra, Portugal \\ ${ }^{2}$ Universidade do Porto \& INESC TEC, Porto
}

\begin{abstract}
This paper discusses the effective contribution of a Learning Object (LO) to teach Circuit Theory based on research conducted with students of higher education, and their interaction with a teacher of Circuit Theory. It presents a prototype model of virtual reality whose goal is to develop skills and competencies and has the ability to be used both as a virtual electrical manual and an educational tool for students in the first year of an Electrical Engineering course. The potential of virtual reality is stressed as being of major usefulness in future study and work scenarios. Virtual Reality (VR) has the advantage of being secure and offers the user the opportunity of being presented with scenarios and conditions that may occur infrequently or may be risky. It is in this perspective that this work was conceived having as goal the development of a $L O$ and the improvement in understanding of physical concepts, in particular those involved with the subject of electrical circuits. It has also as objective to characterize the learning process through a series of situations that are replicated, leading to a set of behaviors from the students. It is assumed that the use of this tool can help acquiring a specific set of skills, a better practice and meaningful learning.
\end{abstract}

Index Terms-Circuit theory, electrical circuits, interactive circuit, learning object.

\section{INTRODUCTION}

The use of information technology as support in education is widespread, and there is varied software developed for educational purposes, the designated Educational Software - ES, playing a greater role in education.

For several authors, all software can be considered an ES since it uses a methodology that contextualizes the teaching-learning process. Quality is the main aspect to be taken into account in choosing this type of software because the market is being increasingly provided with numerous applications and products with the most varied resources.

When using an ES, good pedagogical strategies as well as good quality materials are extremely important for the teaching process. There are two important aspects in an ES: usage and cognitive development as both are directly related in the function of man/machine interaction. To choose it for an educational institution, one must plan it carefully, thinking about tools and processes as well as the team responsible for the implementation of the application in order to get software that is appropriate to provide an effective teaching quality.
Looking for educational software is associated with the ability to meet the requirements of interaction of users but no less important is the ability to promote learning [1].

A computer simulation is an efficient technique for practical work applications. These simulations minimize the concerns of teachers in relation to time, costs or risks that involve the choice of inappropriate, inefficient, or potentially dangerous experimental strategies.

Learning objects (LO) using conceptual text, animation and interactive concept maps are called inclusive. Inclusive education is a process that extends to all students, aiming at personal growth, satisfaction and social integration of all. This is a restructuring of culture and practices experienced in schools to respond to diversity and meet the needs of individual students [2].

The possibility of testing different ways of monitoring the temporal evolution of cause-and-effect relationships, visualizing concepts from different points of view and proving hypotheses makes the animations and simulations a powerful tool to awaken new ideas, relate concepts, arouse curiosity and solve problems. These interactive activities offer opportunities to explore scientific phenomena and concepts, often impractical or nonexistent in schools for economic and security reasons, and allow experiments to be performed outside the classroom [3].

Virtual Reality enables users to examine and manipulate computer-generated, three-dimensional, interactive environments in real-time. VR has developed significantly in recent years and is widely used in many areas [4-6].

Initially it was considered as a tool that required great investment; however, now it allows teaching complex, expensive or hazardous systems in a more cost-effective form, on a computer monitor.

VR systems are considered to be very suitable for visual and spatial representation of the actual physical environments. It is one of the benefits of the curricular units which require test trials and training in procedures.

This paper refers to virtual testing applied to systems of circuit theory, more specifically to laboratory practice focused on teaching and learning. The choice was made from observing that a laboratory needs attendance, measures and instrumentation, which relate primarily to the question of access to the means and equipment to carry out the laboratory practice. So, it was established that the purpose of the work would be the use of virtual experimentation to carry out laboratory practice and as an alternative tool of access to the means and equipment of a specific Instrumentation and Measurements lab. 
Virtual Reality has the advantage of being safe, in addition to providing users with the opportunity of being presented with scenarios and conditions which may occur infrequently or can be risky. Thus, Virtual Reality should not be seen only as an ideal system to improve the training and understanding of students, but it can also play a significant role in the acquisition of skills, reducing failure at school.

\section{Methodological Procedures}

The main objective of this work was the development of an LO for teaching circuit theory. In this perspective, steps were taken to develop a LO: pedagogical design, preparation of courses, production of the object itself and teacher's Guide (Figure 1).

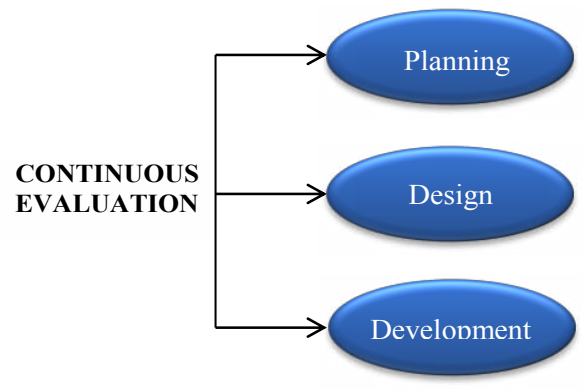

Figure 1. The design and development model

According to Paula Escudeiro, a Learning Object (LO) is a digital interactive feature structured and normalized with a specific educational goal, contents and learning activities and evaluation system [7]. E-contents are any web format contents available on the internet.

The LOs are subsets of e-contents, with interactive contents, structured and standardized according to a format specification and reference model [7]. Currently there are several specification standards for the design of an LO. Paula Escudeiro suggests a normalization of LOs using the SCORM reference model (Sharable Content Object Reference Model). This model supports the development of learning contents in order to ensure reuse, interoperability, durability and good accessibility.

One of the solutions was the development of digital resources (such as video, animation, simulation, etc.) to allow teachers and students to explore specific concepts in circuit theory [8-9].

These interactive activities provide the opportunity of exploring scientific phenomena and concepts, often impractical or nonexistent in schools due to budget and security issues. It also allows experiments to be performed even when a class is not being held.

\section{A. Objectives of educational Software (SE)}

Whereas this LO is nothing more than a sequence of teaching tools that aim at leading the student to learn the physical concept and mathematical relationships involved, the methodology that was used in this research work was Didactic Engineering [10].

To introduce the subject of circuit theory, the student is confronted with a situation in which he interacts with the functionality of one or more devices or assemblies of electrical circuits [11-12]. From there, through the object, the students' curiosity is aroused in order to learn how the process of using the chosen device works. So, a sequence of interactive questions is triggered to lead students to understand it.

According to the contents of Circuit Theory, there is a set of laboratory experiments to provide the student/user with training and knowledge of circuit theory analysis in measurements and instrumentation. The goals are to provide the technical knowledge to analyze electrical circuits of direct or alternating current and to know and understand the various parameters of an electrical circuit: current, voltage, power, energy, power factor, etc.

Every experiment must supply technical/scientific knowledge in order to provide the student/user with experimentation in the syllabus. Virtual trials do not have to be sequential although the sequence of work can help to construct cognitive models required to learn the full contents of the syllabus.

At the end of each virtual simulation, it is expected that the student is able to enter a real laboratory and perform the same work, without feeling any negative impact or maladjustment in relation to the real environment.

In this case, the idea was to build a 3D lab environment (Measures and Instrumentation) where the equipment and components can be seen and manipulated. The project was to build simple electrical schematics that later can be changed in values, presenting new results. The design features a set of menus and submenus to support the experiments [13].

The possibility of testing different ways of monitoring the evolution of cause-and-effect relationships, visualizing concepts from different points of view and confirming hypotheses transforms animations and simulations in powerful tools to promote new ideas and arouse curiosity, relate concepts and solve problems.

\section{Virtual reality technologies}

Technology has brought numerous benefits, extending the scope of the teaching and learning processes, arising as a facilitator and a strategic tool to promote improvement in the methods and practices, optimizing education in general, affording new and innovative opportunities in the way education and teaching are designed.

The latest generation of distance education is characterized by virtual communities with easy-to-use, interactive and accessible e-learning systems. It is also important to mention that distance education is becoming increasingly appropriate for non-academic studies, such as corporate training environments [6].

A virtual distance learning system must incorporate features such as: good accessibility; total control of the educational material; high level of interactivity; a dynamic environment with access to instructional resources; flexibility, allowing the improvisation of teaching materials; self-learning, supplying students with all course materials and promoting their capacity for independent study.

VR systems can be generally classified into four categories, which are determined by their display technology: immersive, semi- immersive, designed and desktop.

As described by Sulbaran, VR tools development can be organized into three main groups [14]: Application Programming Interfaces (API), Software Development Kits (SDK) and authoring tools. 


\section{SPECIAL FOCUS PAPER \\ TEACHING CIRCUIT THEORY USING A DESKTOP VR SYSTEM}

Desktop VR systems display their virtual environments on a conventional PC monitor and the interaction is usually achieved by using the mouse and keyboard [15]. However, these systems can offer support with other visual and interaction devices as the "shutter glasses" and "joysticks", to name just a few. In contrast to the systems described above, the VR desktop offers a much simpler, versatile and less expensive method to develop a VR system although it is achieved at the expense of a less immersive experience.

The software used to achieve the proposed objective was essentially 3Ds Max, VizUp and WireFusion ${ }^{\circledR}$ 5.0. The general idea was to create a three-dimensional model (3Ds Max, Maya, Cinema 4 D, SketchUp, Blender, LightWave or any other 3D tool), reduce the size of the 3D objects with VizUp and then export to WireFusion ${ }^{\circledR}$ 5.0 [16-18].

In WireFusion ${ }^{\circledR}$, there will be the possibility of adding some interactivity and/or animations. However, any animation must be built in the source program of the 3D model. The last step was the production of interactive contents and the introduction of the presentations on the web, using HTML5, CSS3 and JavaScripts offline presentations [18].

The application of VR presented in this work used a WireFusion ( ${ }^{\circledR} 5.0$ authoring tool that allowed the use of an educational license for a relatively short time and cost. This was a significant factor in the choice of this particular application for the development of VEMA (Virtual Electric MAnual). In addition, Wirefusion ${ }^{\circledR}$ does not generate images or 3D models; instead, the application has created a collection of 3D objects, images, animations, 3D meshes and sounds in a separate program and imported them into Wirefusion ${ }^{\circledR}[18]$.

The learning object used in this work is composed by the equipment and the software application available to students in the laboratory. Most of the three-dimensional laboratory objects were modeled with Autodesk ${ }^{\circledR}$ 3Ds Max ${ }^{\circledR}$ software. The 3D animations were also created directly in this tool, as well as the animation of cameras and lights. The data of the animation were included as they were exported to VRML.

Figure 2 shows images of some rendered objects constructed in 3Ds Max which constitute some of the equipment required for the experiments.

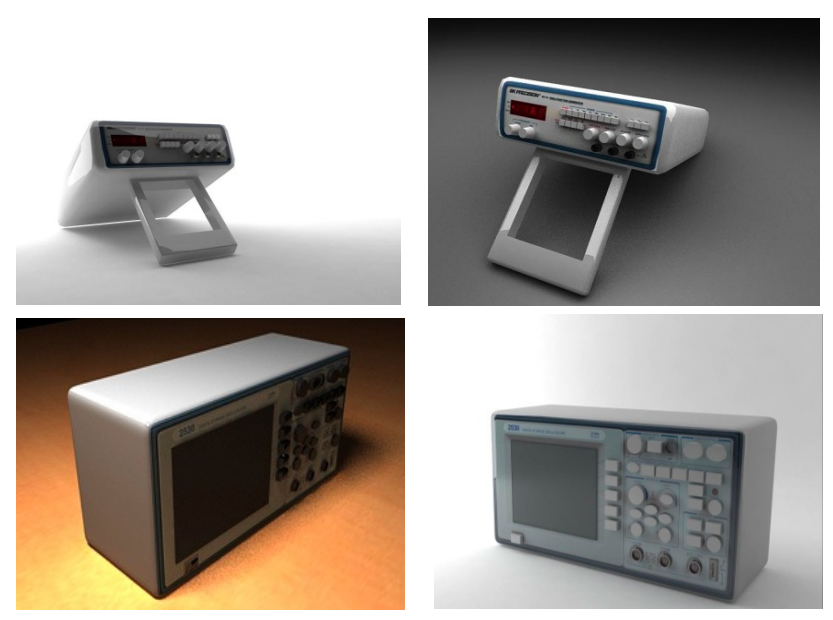

Figure 2. Equipment, Signal generator and Oscilloscope (3Ds Max)

\section{A. Description of the type of educational software}

This paper presents an overview of the systems and tools of VR development, focused on the design process of a VR desktop prototype, Virtual Electric MAnual VEMA. It was developed to demonstrate how VR technology can be applied to an engineering unit and used to enhance security and resourcefulness in using electrical equipment [19].

From the educational point of view, VEMA is not seen as a substitute of the traditional teaching methods, but as a supplementary learning resource that can significantly improve the students' motivation and understanding. VEMA has the potential to involve students and present issues that can be investigated and resolved in their own time. This provides them with an incentive to become more active in their own learning in an environment that relates to the problem.

Engineers could use the application to exemplify some standard aspects. VEMA may also be used as an application for continuous professional development for Technological Specialization courses (TSC).

The basic/main goal of VEMA was to develop a prototype of a VR simulator to demonstrate the potential benefits of combining virtual reality to improve learning in the built-in environment and the concept of measurements in electrical circuits.

The potential target market for the VR system are engineering students, the general public and eventually electrical services and trainers that may benefit from the instructions contained in the virtual electric manual [1920].

The initial development phase of the application required the construction of $3 \mathrm{D}$ models of all the objects/equipment in measurements and instrumentation laboratories, using a conventional 3D modeling software (Figure 3).



Figure 3. Virtual laboratory environment created for the VEMA application

Figure 3 shows the laboratory setting with the layout of the workbench and the desired equipment. In this image the AutoCAD software "memorized" the indoor lab scenario, the background of the countertop plan, as Xref.

3D Studio Max modeling geometric detail has been sacrificed to ensure the full optimization of the software rendering in real time, which could be negatively affected by the complex geometry and excessive texture sizes. 
Usability studies of virtual environments have demonstrated that users tend not to identify or that they are oblivious of what is interactive or not. Making sure that the appliances are clear potentially improves interactive usability and helps in preventing students' frustration that, ultimately, can reduce the effectiveness of the application as a training tool.

Various interactive scenes were developed to illustrate this aspect using a Measurements and Instrumentation laboratory as virtual environment (Figure 4).

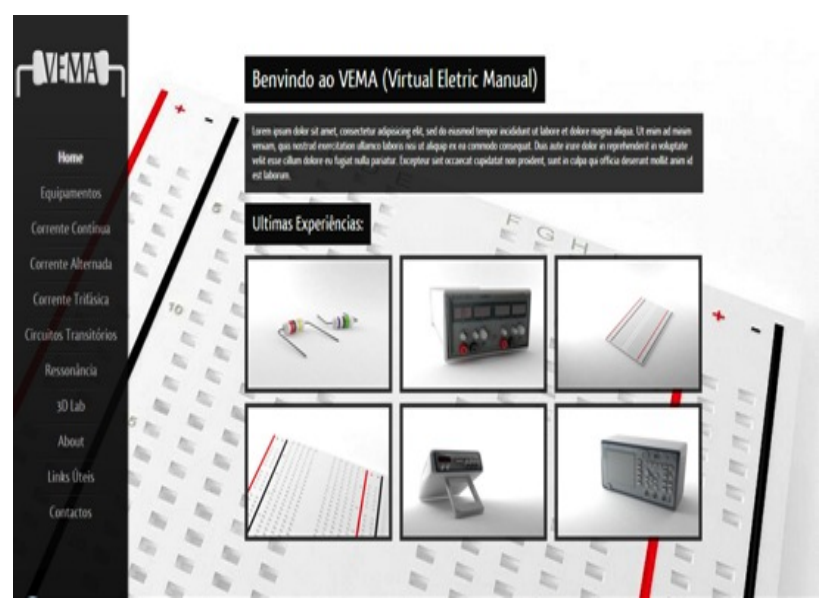

Figure 4. Home page of VEMA

The menus on the left side of the screen are the keys where the desired experience can be selected by the students (Figure 4). With them, students can open different windows. Some unusual functions of the devices are not implemented.

Inside the simulator, the student can "walk" on the virtual laboratory facility and interact or simulate a value in any of the interactive devices, such as a power supply, resistors, etc. By varying these parameters the circuit is automatically updated and the student can instantly see the impact of their choices.

In order to provide the highest degree of realism and in compliance with appropriate main electrical measures and instrumentation laboratories, models were set for the VEMA application: visual representation of apparatus, equipment or electric mounts in the built environment; simulation and representation of the functionality of the assembling of appliances and equipment. In addition, VEMA has to ensure interactivity, be intuitive and provide accessibility of the application in a wide range of platforms.

The application of the VEMA prototype consists, therefore, in experimental interactive scenes. A user interface allows the student to get in and out of each scene in an intuitive way.

\section{CONCLUSION}

Simulations and animations of LOs should provide practice similar to the one acquired in real life and thus become a viable resource in situations where practical sessions cannot be carried out. Therefore, it is considered that the LOs can assist the lectures in the acquisition of concepts as well as provide support for the theoreticalpractical and laboratory lessons, integrating the instruments that allow cognitive learning based primarily on student interaction with the desired environment.

Familiarity with the virtual environment can enable students to become quickly absorbed in small electrical projects. This way, the student can easily identify the parameters involved and thus develop a greater familiarity with the possibility to learn to design an electrical circuit with greater confidence and safety [21].

The adoption of a circuit simulator "direct current" as a pedagogical instrument is a student-centered approach and moves from conventional learning techniques to a form of internship where students can self-learn, investigate results of data reached in their own convenient timing. The use of virtual reality as a training tool to teach students and users in general about the problem of electric circuits is an exciting and innovative perspective [8]. The access to instructions, via VR, can perhaps help and also provide students with a clearer interpretation and a deeper understanding of the rules [15].

Because the desktop VR applications are reusable and easily updated, they can potentially reduce the costs in training and can be made available through the web, ultimately becoming a very attractive option for education and industry. Virtual reality provides an opportunity to deepen understanding, raises awareness about procedures, and trains students to interact with the equipment [9]. The VEMA prototype addresses these issues and highlights the potential benefits of the use of VR for this purpose [12].

Each experiment should provide technical/scientific knowledge in order to provide the student/user with the understanding and skills on the course contents. Virtual trials do not have to be sequential but the sequence of work can help students to learn about the full contents of the syllabus.

Computer simulation is an efficient technique to be used in practical work as it minimizes the teachers' concerns regarding time, costs or risks that involve the choice of inappropriate, ineffective or potentially dangerous experimental strategies.

Currently, there aren't many organizations or training schools using virtual reality this way. One of the goals of this study is to highlight the potential that VR offers the institutions with regard to improved understanding of electrical circuits. If VR can enhance the effect of learning, it could be argued that VR can lead to greater adherence to standards and, consequently, an overall improvement in security in the handling of electrical circuits and equipment in the laboratory environment.

The importance of this work is stressed by its interdisciplinary character as three distinct areas are interrelated: Electrical Measurements, widely used in laboratory environment and stimulating students to learn more about this subject; Mathematics, allowing to characterize and understand the physical phenomena present in the LO; and Computer Science, an area that promotes understanding of the subjects because it facilitates the understanding of the contents of Electrical Measurements, Circuit Theory and Mathematics, its visualization, and interaction with the student.

VEMA is an application built using a VR desktop system and designed to improve training and the practical performance in a laboratory environment. It enables the "navigation" within a virtual environment and interaction with some electrical components. No browser plug-in is 
required to view the presentations. WireFusion ${ }^{\circledR}$ is a Java applet which is downloaded to the user's browser, as well as other files on the web server, using the HTTP protocol [18].

As a pedagogical instrument, it is a student-centered approach where they can self-learn and investigate the results of their own data in their own time [22-24].

It is in this perspective that this work was conceived, having as goal the development of a LO, assuming that it may be a possible alternative to represent models of interactions that occur within the object of study. It may help improve the understanding of physical concepts, in particular those involved in the subject of electrical circuits. It aims at characterizing the learning process through a series of situations that can be repeated, leading to a change of attitude and involvement of students. It is assumed that the use of this tool can lead to the acquisition of a specific set of skills, a better and meaningful practice and significant learning.

The VEMA prototype is in its initial phase and undergoing a thorough evaluation of its system.

\section{REFERENCES}

[1] A. Ruplis, E. Priednieks. "Recent Development of Some Learning Tools for Course". Electrical Engineering and Electronics, ISSN 1392 - 1215, Nr. 7, 2006, Page(s): 71.

[2] M. G. da Silva, M. A. Fernandez, "Recursos informáticos projetados para o ensino de ciências: bases epistemológicas implicadas na construção e desenvolvimento de objetos de aprendizagem". In Objetos de Aprendizagem: uma proposta de recurso pedagógico. Brasília: MEC, SEED, ISBN: 978-85-2960093-2, 2007, pp. 27-37 (in Portuguese).

[3] G. Hong-liang, and L. Shengman, "Virtual Reality Technology and its Application in Prevention of Coal and Gas Outburst". In Second International Conference on Information and Computing Science, Manchester, 2009, pp. 110-113.

[4] Li Shuang, "Research on Application of Virtual Reality Technology in Teaching and Training", in Second International Conference Computer and Electrical Engineering, ICCEE '09. Dubai, 2009, pp. 77 - 80.

[5] Sharples, S., Cobb, S., Moody, A. and Wilson, J., R., "Virtual reality induced symptoms and effects (VRISE): Comparison of head mounted display (HMD), desktop and projection display systems", Displays, vol. 29, no. 2, March 2008, pp. 58-69. http://dx.doi.org/10.1016/j.displa.2007.09.005

[6] B. Z. Perez, M. M. Marin and E. I. Perez, "Developing a Virtual Environment for Safety Training", in Electronics, Robotics and Automotive Mechanics Conference, Morelos, 2007, pp. 545 - 550. http://dx.doi.org/10.1109/CERMA.2007.4367743

[7] P. M. S. Oliveira Escudeiro, "Prototipificação Evolutiva de Software Educativo Suportado por Bases de Dados Relacionais", Universidade Aberta, Ph. D. thesis, 2008 (in Portuguese).

[8] Z. Dong, J. Lucas and W. Thabet. "Using virtual environments to support electrical safety awareness in construction". In Proceedings of the 2009 Winter Simulation Conference, 2009, pp. $2679-2690$.

[9] B. Z. Perez, M. M. Marin, and E. I. Perez, "Developing a Virtual Environment for Safety Training". In Electronics, Robotics and Automotive Mechanics Conference, Morelos, 2007, pp. 545 - 550. http://dx.doi.org/10.1109/CERMA.2007.4367743

[10] I. S. L. Lima, H. A. de Carvalho, K. Schünzen Junior, E. T. M. Schlünzen, "Criando Interfaces para Objetos de Aprendizagem." Em Prata, C.L. Nascimento, A.C.A. (orgs). Objetos de aprendizagem: uma proposta de recurso pedagógico. Brasília: MEC, SEED, 2007, pp. 39-48.

[11] M. M. Travassos Valdez, C. M. Machado Ferreira and F. P. Maciel Barbosa, "Ferramenta Computacional Educativa para Simulação de Circuitos Eléctricos". INTERTECH'2010, XI International Conference on Engineering and Technology Education, Ilhéus, Baía, Brasil. 2010. (in Portuguese).
[12] M. M. Travassos Valdez, C. M. Machado Ferreira and F. P. Maciel Barbosa, "Software Packages to Support Electrical Engineering Virtual Lab". International Journal on Emerging Technologies in Learning, iJOE2012. ISSN: 1861-2121. Volume 8, Special Issue 2: exp.at'11, 2012, pp. 19-23, Special Focus Papers.

[13] M. M. Travassos Valdez, Ferreira, C. M. Machado and F. P. Maciel Barbosa, "3D Virtual Labs for Internet Application". IEEExplore2011. International Journal of Online Engineering, iJOE. 2011.

[14] T. Sulbaran and M. F. Shiratuddin, "A Proposed Framework for a Virtual Reality Training Tool for Design and Installation of Electrical Systems", in 6th International Conference of Construction on Construction Applications of Virtual Reality, Orlando, Florida, 2006.

[15] Ai-Lim Lee Elinda, Kok Wai Wong, and Che Fung Chun, "How does desktop virtual reality enhance learning outcomes? A structural equation modeling approach". Computers \& Education, $2010, \quad$ vol. 55, pp. 1424-1442. http://dx.doi.org/10.1016/ j.compedu.2010.06.006

[16] 3Ds Max. Autodesk ${ }^{\circledR}$ 3Ds Max Design $®$. Available from: http://usa.autodesk.com/3ds-max/\#. [Accessed June 10, 2012].

[17] VizUp., VizUp, software company - Optimize 3D models. Available from: http://www.vizup.com/index.html [Accessed April 2012].

[18] WireFusion. WireFusion - Realtime interactive 3D for internet marketing, 3D configurators and product visualizations, 2009, Available from http://www.demicron.com/wirefusion/ [Accessed June 27, 2012].

[19] B M. A. M.albed, N. Ibrahim, and A. M. Yusof. "Implementation of Virtual Environment Using Virtools. Computer Graphics, Imaging and Visualisation". CGIV '08, Fifth International Conference, 2008, pp. $101-106$.

[20] Dalgarno Barney and J.W. Lee Mark. "What are the learning affordances of 3-D virtual environments?". British Journal of Educational Technology, 2010, vol. 41, no. 1, pp. 10-32. http://dx.doi.org/10.1111/j.1467-8535.2009.01038.x

[21] N.Adamo-Villani, E. Johnson and T.Penrod, "Virtual Reality on the web: the 21 st Century World project," in International Conference on Multimedia and Information and Communication Technologies in Education, Lisbon, 2009.

[22] Huang Hsiu-Mei, Rauch Ulrich, and Liaw Shu-Sheng. "Investigating learners' attitudes toward virtual reality learning environments: Based on a constructivist approach". Computers \& Education, 2010, vol. 55, no. 3, pp. 1171-1182. http://dx.doi.org/10.1016/j.compedu.2010.05.014

[23] B. P. Butz, M. Duarte, and S. M. Miller, An intelligent tutoring system for circuit analysis, IEEE Trans Educ 49 (2006), 216-223. http://dx.doi.org/10.1109/TE.2006.872407

[24] R. Volner, "Engineering Environment and Avionics Virtual Prototyping". Electronic technical journal, Number 2, Volume VII, ISSN 1801-674X, July 2012.

\section{AUTHORS}

M. Travassos Valdez is with the Department of Electrical Engineering, Coimbra Polytechnic Institute (ISEC), Coimbra, Portugal (e-mail: valdez@ isec.pt).

C. Machado Ferreira is with the Department of Electrical Engineering, Coimbra Polytechnic Institute (ISEC), and INESC Coimbra, Coimbra, Portugal (e-mail: cmacfer@isec.pt).

F. P. Maciel Barbosa is with the Department of Electrical Engineering and Computers, Faculty of Engineering of the University of Oporto, (FEUP) and INESC TEC Porto, Porto, Portugal (e-mail: fmb@fe.up.pt).

This article is an extended and modified version of a paper presented at the EDUCON2013 conference held at Technische Universität Berlin, Berlin, Germany from March 13-15, 2013. Submitted, 22 April 2013. Published as re-submitted by the authors on 16 May 2013. 